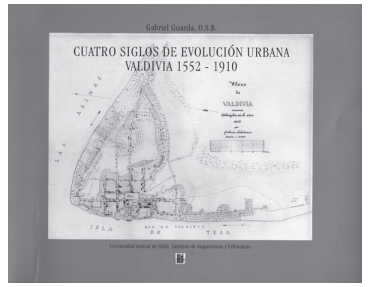

\title{
Gabriel Guarda. Cuatro siglos de evolución urbana. Valdivia 1552-1910
}

\author{
Valdivia: Instituto de Arquitectura y Urbanismo, \\ Universidad Austral de Chile, 2009. 83 p.
}

\author{
Alex Paulsen E. ${ }^{1}$
}

"En el espacio leemos el tiempo" según Karl Sholögel (2007), frase sugerente para el libro de esta reseña, ya que sus páginas no contienen una reflexión profunda del desarrollo urbano de Valdivia, sino que habla de su historia urbana a través de fotografías y planos que han sido construidos (en virtud de fuentes primarias y visitas en terreno en el centro de la ciudad para encontrarse con rastros del pasado) y en más de algún caso descubiertos en alguna lejana biblioteca. Asimismo, y siguiendo la misma línea de investigación que en otros estudios del autor, se incluye la división predial, con las correspondientes subdivisiones generadas por la compraventa de terrenos, así como también debido a sucesiones hereditarias.

Gabriel Guarda, arquitecto, historiador y Premio Nacional de Historia en 1984, presenta la evolución urbana de Valdivia desde 1552 hasta 1910. A prima facie, se podría pensar en un libro de gran envergadura teniendo en cuenta el marco temporal en el que se inserta, sin embargo, y como se ha señalado anteriormente, su desarrollo transcurre a través de planos que evidencian el cambio urbano de Valdivia antes de la destrucción de las siete ciudades (1599)² hasta el Ilamado Gran Incendio de diciembre de 1909.

\footnotetext{
1 Magister (C) en Geografía y Geomática. Instituto de Geografía, Pontificia Universidad Católica de Chile (Chile).E-mail: appaulse@uc.cl

2 Posteriormente, Valdivia no será refundada hasta 1645, luego de que fuese ocupada por holandeses dos años anteriores. "La población surgente será desde entonces Plaza Real pero no alcanzará jamás las proporciones y rango de la antigua" (Guarda, 1994: 128).
}

La ciudad de Valdivia ha sido parte de una historia bastante particular, ya que se pueden contar una cantidad importante de desastres naturales y terremotos que la han afectado de forma decisiva en lo que se refiere a su desarrollo urbano. En tal sentido, el primer acontecimiento de envergadura lo constituye el alzamiento indígena que devastó a la mayoría de las ciudades del sur. Para el caso de Valdivia, "el 24 de noviembre, poco antes de amanecer, cayeron sobre la ciudad, cerraron todas las bocacalles para impedir la fuga, y emprendieron el asalto, sin que nadie se diera cuenta hasta tener las lanzas de los indios abocadas al pecho. Ocuparon el fuerte, sin encontrar en él un solo soldado. Pusieron fuego a la ciudad, despedazaron las imágenes de las iglesias y se entregaron al saqueo y al libertinaje. Cuando ya nada les quedó por destruir, se retiraron... (...) Con la destrucción de Valdivia, desapareció una de las más prósperas ciudades del sur y la llave de todos los establecimientos españoles en la región" (Encina, 1950: 307-308).

Luego de este gran acontecimiento ${ }^{3}$ Valdivia quedó indocumentada en lo que se refiere a fuentes propias del siglo XVI. No obstante, ¿cómo es posible que el primer plano que presenta este libro muestre la situación urbana de Valdivia al momento de su destrucción

\footnotetext{
3 Se toma la palabra acontecimiento de acuerdo a la acepción de Fernand Braudel: "¿Qué es, de hecho, un gran acontecimiento? No el que hace más ruido cuando ocurre, como les decía hace un instante, sino el que acarrea las mayores consecuencias, en número y en importancia. Las consecuencias no se producen en lo inmediato, las consecuencias son hijas del tiempo" (Braudel, 2002: 38).
} 
en 1599? Al verificar la fuente de este plano figura el nombre de la Biblioteca de la Universidad de Göttingen de Alemania y, remitiéndose a otra obra de este mismo autor, se aprecia que dicho documento fue hallado por el embajador de Chile José Miguel Barros en dicha biblioteca, con lo que el conocimiento sobre Valdivia tomó un nuevo rumbo.

¿Cuál es la relevancia de este plano reconstruido por una expedición holandesa asentada en dicho lugar hacia 1643? Principalmente que "unidos a los testimonios de las crónicas o de los documentos que aquí o allá salvaron de aquella catástrofe, los datos que suministra el plano holandés pone de manifiesto una inimaginada realidad: que la ciudad, en el mismo siglo de su fundación, se presenta sorprendentemente estructurada en su aspecto urbano, con una novedosa red vial e interesantes detalles de carácter edilicio" (Guarda, 1994: 15). En comparación con otras ciudades de Chile, este plano demostraría que la ciudad de Valdivia presentaba rasgos muy diferentes y únicos en lo que se refiere a su trama urbana. De igual forma, "la singularidad de su traza, con predominio de cuadras apaisadas, al revés de la tradicional cuadrícula de manzanas de cuatro solares; la constante alteración de su traza, por efecto de accidentes naturales o por razones militares, derivadas de lo estratégico de su situación dentro del Pacífico; en fin, al revés de auténticas constantes observadas en la mayoría de las fundaciones indianas, no se mantendrá la traza original, ni la locación de sus edificios públicos, ni de sus iglesias ni, dentro de las calles, una línea clara de edificación" (Guarda, 2009: 1) Incluso, ya en aquella época se encuentran testimonios que hacen expresa alusión a las características urbanas de Valdivia, a saber, Diego de Rosales relata lo siguiente: "la planta de la población de esta ciudad fue semejante a la Triana (célebre arrabal de Sevilla), porque se extendió río arriba por gozar de su amena vista" (Guarda, 1994: 26).

En consecuencia, no es posible realizar una descripción acabada del desarrollo urbano de Valdivia, sin tomar en cuenta no tan solo su historia política o militar, sino que también, y para no caer en reduccionismos, su historia ambiental. A pesar de que el autor del texto no realiza un análisis detallado de los sucesos naturales que han afectado a la ciudad, sí los menciona someramente ${ }^{4}$ dentro de la introducción del libro: "hemos podido contar a lo menos trece incendios generales -en 1682, 1737, 1742, 1748, 1785, (dos), 1789, 1793, 1803, 1859, 1854, 1904-, hasta el Ilamado Gran Incendio, de diciembre de 1909, que arrasó dieciocho cuadras del centro histórico y que hemos elegido como hito y límite del presente estudio; a lo que debe agregarse el inusual número e intensidad de terremotos, a lo menos ocho, en 1575, 1730, 1737, 1751, 1835, 1837, 1906 y 1960, este último, el más grande registrado hasta el presente en el planeta, con características idénticas al de 1575, según el testimonio transmitido por las crónicas. Como si todo lo anterior fuese poco, debe añadirse una tromba marina que, al igual que las registradas en el Caribe, arrasó precisamente el centro de la ciudad, en abril de 1881,..." (Guarda, 2009: 1).

Esto último revela la concepción holística, epistemológica e interdisciplinaria ${ }^{5}$ que el padre Gabriel posee sobre la historia urbana, tratando no tan solo aspectos referidos a lo urbano, sino que también atiende otras variables de suma importancia, las que sin lugar a duda juegan un rol significativo en el desarrollo de toda ciudad. Ergo, su concepción de esta disciplina estaría referida a "una rama de la historia que se ocupa del estudio del pasado de las ciudades en aspectos muy amplios y variados: políticos, económicos, sociales, formales y culturales principalmente. Podría considerarse como una forma de historia total, que abarca los aspectos más importantes de la vida de las ciudades" (Fuentes, 1999: 52). Esto se ve plasmado en sus estudios con erudición, por cuanto sus fuentes permiten apreciar una acuciante búsqueda e interrogación de las mismas.

\footnotetext{
4 Para un desarrollo más extenso de los fenómenos naturales que han ocurrido en Valdivia, véase Guarda, 1994.

5 "Desde que Pierre Lavedan en su ya clásica Historie de L' Urbanisme destacó la importancia de las ciudades hispanoamericanas en el periodo indiano, el interés que en los círculos científicos ha despertado el proceso urbanizador de estos países no solo ha centrado la atención de los historiadores e investigadores del pasado, sino a cuantos se preocupan del desenvolvimiento presente de las ciudades..." (Guarda, 1978: 9).
} 
Ahora bien, lo que está explícitamente presente en este libro es una crítica bastante aguda con respecto al tratamiento de las ciudades, específicamente a su participación en el desarrollo del proceso independentista, en la historiografía chilena del último tiempo. Frente a tal cuestión, no menor, el autor señala lo siguiente: "nuestra historiografía ha sido tremendamente centralista, nuestros principales autores ignoraron completamente Valdivia y Chiloé, no obstante el hecho de que tuvieran a la vista la abundancia de documentación referente a estas zonas, que duplica o triplica a la relativa a Santiago y la zona central; una historiografía dedicada exclusivamente a relatar sucesos político militares vistos al calor de las guerras de la independencia debía necesariamente omitir la mención a escenarios que no tuvieran por protagonismo la capital y su habitantes; menos se les podía pedir sensibilidad frente a temas estéticos o de valor patrimonial" (Guarda, 2009: 3). Este no es un malestar propio de este autor, ya que otros historiadores también han hecho alusión a esta problemática ${ }^{6}$.

Finalmente, este libro cuenta con una sección que se denomina "Estudio de la división predial. Matriz: Plano de Siemsen" ${ }^{7 "}$, donde es posible hallar, en primera instancia, los principales hitos patrimoniales de Valdivia, las principales iglesias y conventos (entre 1552 y 1960) y de domicilios singulares (verbi gratia, la casa de gobernadores y colegios) con su respectiva ubicación en distintas épocas ${ }^{8}$. Posteriormente, el padre Guarda identifica los propietarios de diversos predios (específicamente 48 cuadras ubicadas en el sector norte de Valdivia) en diferentes años. Aunque la lectura de este último acápite pueda resultar tediosa (en

6 Otro historiador que se ha referido a este debate es Mateo Martinic, Premio Nacional de Historia en el año 2000. Mayor información sobre este mismo autor en Parentini (2008). Es menester señalar que estos autores pertenecen a Valdivia, para el caso del padre Gabriel Guarda, y a Magallanes para el caso de Mateo Martinic.

7 Plano que fue elaborado por el ingeniero Enrique Siemsen en 1855 , el que es utilizado para un estudio de elementos-testigos de carácter patrimonial.

8 En virtud de diferentes sucesos históricos y naturales, los hitos patrimoniales cambiaron de ubicación o definitivamente dejaron de existir. palabras del mismo autor, esta lectura "necesariamente debe resultar farragosa"), su información es bastante relevante ya que muestra cómo la colonización que se produce a partir de 1850 por inmigrantes alemanes, se refleja en el cambio de residentes con apellidos castellanos a apellidos de origen alemán. "Después de un intento por cuenta privada, realizado en 1846 en la hacienda Bellavista, en los alrededores de Río Bueno, la corriente migratoria se regulariza a partir de 1850, año en que comienzan a llegar los grupos más selectos. (...) El flujo colonizador se mantiene hasta 1876, en que comienza a languidecer. Se calcula globalmente en unos 7.800 el número de alemanes venidos al país durante este tiempo" (Guarda, 1979: 63). La impronta que marcarán estos nuevos habitantes en la ciudad de Valdivia será tal que se podrán apreciar frases tales como: "Quien diría ahora diez años que en Valdivia pudieran funcionar dos teatros a la vez y tan bien arreglados" (Guarda, 1979: 65).

\section{Consideraciones finales}

El padre Gabriel Guarda nuevamente viene a hacer gala de su prolijidad, erudición y manejo de las fuentes al momento de llevar a cabo una disciplina tan compleja como la historia urbana, lo cual se refleja en este texto. Si bien, este es un trabajo hecho en colaboración con profesores y estudiantes de arquitectura del Instituto de Arquitectura y Urbanismo de la Universidad Austral de Chile, en el estudio se puede evidenciar claramente años y años de investigación por parte del autor del texto, ya que tanto los mapas como el acopio de información que se pueden apreciar, son parte de escritos anteriores. Sin embargo, esto no le quita mérito, ya que es un libro que puede ser bastante evocador, por cuanto trae interrogantes bastante apremiantes en la labor del historiador o del geógrafo, a saber: ¿cómo interrogar los mapas?, ¿cómo apreciar en buena forma el valor de una fuente primaria?, ¿de qué forma el historiador toma dentro de sus variables al espacio y lo utiliza para sí?, por su parte, ¿el geógrafo considera el tiempo pretérito (o quizás el patrimonio de dicho lugar) al momento de espacializar los fenómenos que investiga?

A pesar de no tener una respuesta a estas inquietudes, queda la sensación de que el 
texto intenta advertir que "en el espacio leemos el tiempo".

\section{Referencias bibliográficas}

BRAUDEL, F. Las ambiciones de la historia. Barcelona: Editorial Critica, 2002.

ENCINA, F. Historia de Chile. Tomo II. Santiago: Editorial Nascimento, 1950.

FUENTES, M. Diccionario de historia urbana y urbanismo. El lenguaje de la ciudad en el tiempo. Madrid: Universidad Carlos III de Madrid, 1999.

GUARDA, G. Cuatro siglos de evolución urbana. Valdivia 1552-1910. Valdivia: Universidad Austral de Chile, Instituto de Arquitectura y Urbanismo, 2009.
GUARDA, G. Historia urbana del reino de Chile. Santiago: Editorial Andrés Bello, 1978.

GUARDA, G. La sociedad en Chile austral antes de la colonización alemana 1645-1845. Santiago: Editorial Andrés Bello, 1979.

GUARDA, G. Una ciudad chilena del siglo XVI. Valdivia 1552-1604. Urbanística. Res publica. Economía. Sociedad. Santiago: Ediciones Universidad Católica de Chile, 1994.

PARENTINI, C. (comp.). Historiadores chilenos frente al bicentenario. Santiago: Ed. Bicentenario Presidencia de la República, 2008.

SCHLÖGEL, K. En el espacio leemos el tiempo. Sobre historia de la civilización y geopolítica. Madrid: Ediciones Siruela, 2007. 